\title{
Radiographic Evaluation of Hip Implants
}

\author{
Connie Y. Chang, MD ${ }^{1}$ Ambrose J. Huang, $\mathrm{MD}^{1} \quad$ William E. Palmer, MD ${ }^{1}$ \\ ${ }^{1}$ Division of Musculoskeletal Imaging and Intervention, Massachusetts \\ General Hospital, Harvard Medical School, Boston, Massachusetts \\ Address for correspondence Connie Y. Chang, MD, Division of \\ Musculoskeletal Imaging and Intervention, Massachusetts General \\ Hospital, Harvard Medical School, 55 Fruit Street, Yawkey 6E, Boston, \\ Semin Musculoskelet Radiol 2015;19:12-20. \\ MA 02114 (e-mail: cychang@mgh.harvard.edu).
}

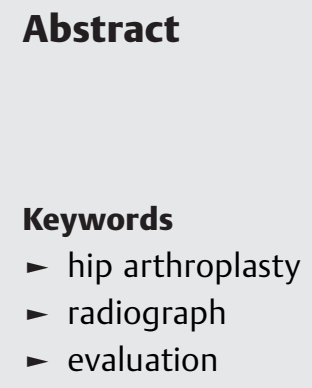

Serial radiographs are the mainstay in the longitudinal assessment of hip implants. The prosthesis, periprosthetic bone, and juxta-articular soft tissues are inspected for fracture, periosteal reaction, stress shielding, calcar resorption, osteolysis, bony remodeling, metallic debris, and heterotopic ossification. Comparison radiographs best confirm implant migration, subsidence, and aseptic loosening. Infection, particle disease, reaction to metal, and mechanical impingement are important causes of postsurgical pain, but in their earliest stages they may be difficult to diagnose using radiographs. This article addresses the role of radiography following hip arthroplasty.
According to the Centers for Disease Control and Prevention, $\sim 328,000$ total hip arthroplasties and 332,000 hemiarthroplasties were performed in 2010 in the United States. ${ }^{1}$ Among patients choosing surgery for osteoarthritis, $89 \%$ report satisfaction due to pain relief, functional improvement, and quality of life. ${ }^{2,3}$ Resurfacing arthroplasties are less common procedures with comparatively mixed results. ${ }^{4}$

Serial radiographs of the pelvis, hip, and femur are routinely performed in the asymptomatic or symptomatic patient as a screening tool or first-line examination. ${ }^{5}$ They are used to detect hardware complications and monitor disease progression. ${ }^{6}$ Although cross-sectional studies have important roles in evaluating and characterizing abnormalities of periprosthetic bone and juxta-articular soft tissues, standard radiographic views facilitate longitudinal comparison with minimal or no metal artifact. In patients with hip pain, they complement clinical assessments and laboratory tests including erythrocyte sedimentation rate and C-reactive protein in suspected infection. ${ }^{7,8}$ Serum and urine ion levels (cobalt and chromium) are frequently measured due to an increased awareness of reaction to metal as a complication of arthroplasty. ${ }^{9,10}$

\section{Arthroplasty Types}

Hip prostheses can be categorized as total or partial (hemi-) arthroplasties. Total hip arthroplasties (THAs) are most commonly performed for osteoarthritis and can be subcategorized by the articular bearing surface: hard on hard (ceramic on ceramic, metal on metal) or hard on soft (metal or ceramic on polyethylene). ${ }^{6}$ In hemiarthroplasties, the femoral head is replaced for conditions sparing the acetabulum and affecting only the proximal femur, such as femoral neck fracture and capital femoral necrosis. Hemiarthroplasties can be subdivided into unipolar and bipolar implants. The unipolar prosthesis has a single articulation between the femoral head component and the native acetabulum. The bipolar prosthesis has a small internal bearing that moves within a polyethylene-lined shell. This shell then articulates with the native acetabulum. ${ }^{11}$

In the 1990s, resurfacing arthroplasty (RA) became a popular choice in the young, active patient with solid bone stock. Indications quickly expanded to included older active patients as well as individuals with inflammatory arthropathy, fracture deformity, or postoperative change. Instead of replacing the entire femoral head and neck, a cap is placed on the femoral neck, which is preserved. Currently, RAs are a predominantly metal-on-metal bearing with noncemented acetabular and cemented femoral components (Birmingham resurfacing technique), in which the cement is hidden beneath the femoral head. The metaphyseal stem may be cemented or noncemented ( - Fig. 1). ${ }^{12,13}$ Compared with THAs, RAs have the advantage of bone stock preservation that enables conversion to THA later in life. Other advantages include stability with decreased dislocation, functional outcome, lower rates of aseptic loosening, and higher 5-year survival. These advantages are counterbalanced by important risks such as femoral neck fracture, necrosis of the femoral head remnant, and reaction to metal leading to osteolysis,
Issue Theme Imaging of Joint Replacements; Guest Editor, Theodore T. Miller, MD, FACR
Copyright $\odot 2015$ by Thieme Medical Publishers, Inc., 333 Seventh Avenue, New York, NY 10001, USA. Tel: +1(212) 584-4662.
DOI http://dx.doi.org/ 10.1055/s-0034-1396763. ISSN 1089-7860. 


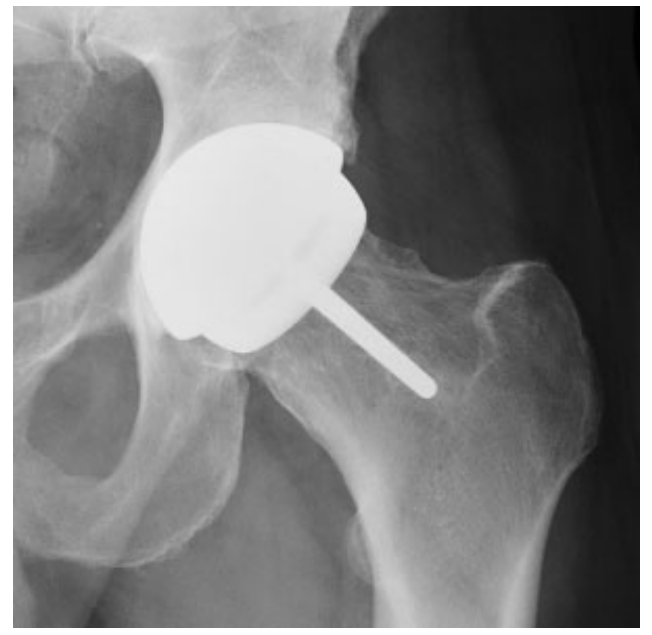

Fig. 1 Frontal radiograph of the left hip in a 60-year-old man showing normal appearance of a resurfacing arthroplasty. The femoral head is cemented, but the cement is not visible on radiographs. The metaphyseal stem is noncemented. There is no periprosthetic lucency, and the femoral stem is essentially parallel to the long axis of the femoral neck.

pseudotumor, and chromosomal translocations in adjacent tissues due to the shedding of metal ions in the first 2 years (the wearing-in phase). ${ }^{9,10,14-20}$

\section{Radiographic Technique, Evaluation, and Abnormalities}

Evaluation of the arthroplasty begins with a frontal view of the pelvis (-Fig. 2). Additional orthogonal views, either a "frog leg" or cross-table lateral, are valuable in assessing the anteroposterior axis of the implant and the orientation of the acetabular component. Radiographs must include a margin around the prosthesis to evaluate the adjacent bony and soft tissue structures. $^{21,22}$

Proper alignment of the THA is important for longevity and stability. The inclination (abduction angle) of the acetabulum should be $\sim 45$ degrees (range: 35-55 degrees). Acetabular version should be $\sim 20$ degrees of anteversion (range: 10-30 degrees) and is evaluated on a cross-table lateral radiograph. However, because anteversion is affected by pelvic or thigh rotation, version should not be measured in these cases, and only extreme anteversion or the presence of retroversion should be noted. ${ }^{2,23}$ The vertical and horizontal centers of rotation are also important to evaluate. If the component is placed too high, the surrounding muscles will be lax. If the component is too low, the stretched muscles may go into spasm. In both situations, the muscles are less effective in stabilizing the joint. In a normal hip, the iliopsoas tendon passes just lateral to the center of the femoral head, and therefore iliopsoas contractions help to stabilize the joint. If the component is placed too lateral, and the tendon passes medial to the center of the femoral head, iliopsoas contractions will destabilize the joint, increasing the probability of dislocation. Finally, the position of the femoral stem should be evaluated. For a noncemented femoral component, a neutral position within the medullary canal is optimal. Slight valgus position of the femoral stem, where the distal aspect of the femoral stem is directed toward the medial femoral endoste$\mathrm{um}$, is generally acceptable. Varus position of the femoral stem, where the distal aspect of the femoral stem is directed toward the lateral femoral endosteum, increases the risk for early loosening. ${ }^{24}$

The femoral component of a RA should be $\sim 5$ to 10 degrees valgus relative to the femoral neck. Varus or excessive valgus angulation can lead to notching and fracture or loosening as a result. Depending on the manufacturer, the acetabular component should be in 30 to 50 degrees of abduction and 15 to 25 degrees of anteversion. ${ }^{25,26}$

On radiographs, the location of an osseous lucency adjacent to the acetabular component can be described according to DeLee and Charnley ${ }^{27}$ zones, and the location of an osseous lucency adjacent to the femoral components can be described according to Gruen zones on the frontal and lateral views (-Fig. 3). 2,28 Lucency around the femoral component of a resurfacing arthroplasty stem should be described according to the system developed by Amstutz et al. Zone 1 is the area superior to the stem, zone 2 is the area at the stem tip, and zone 3 is the area inferior to the stem (-Fig. 4). ${ }^{13}$

A well-fixed noncemented acetabular component may demonstrate close apposition to the bone without any lucency around the component, medial stress shielding, superolateral buttressing (-Fig. 5), inferomedial buttressing, and a radial trabecular pattern in the periacetabular bone (-Fig. 6). If three or more of these findings are present, the positive a

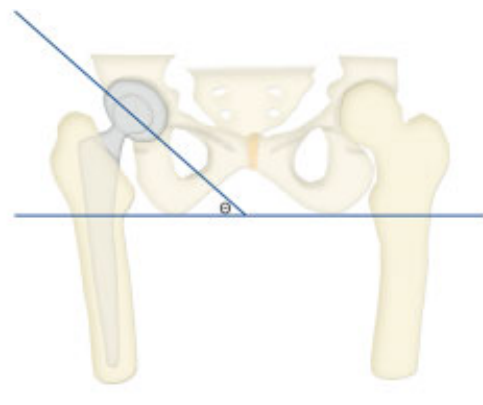

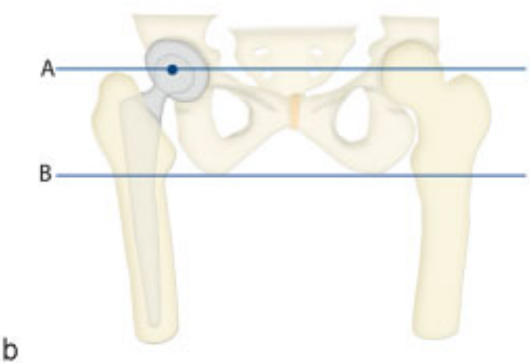

c

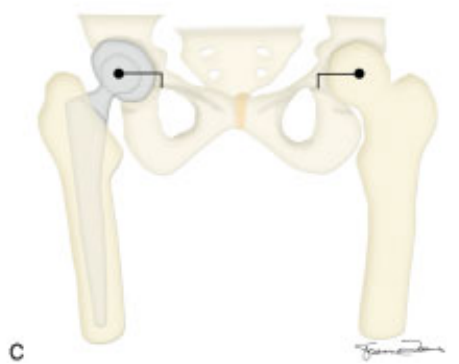

Fig. 2 Schematic of frontal view of the pelvis with a right total hip arthroplasty. (a) The inclination of the acetabular component ( $\theta)$ is the angle it makes with the transischial line. (b) The vertical center of rotation is the vertical distance from a line joining the centers of the femoral heads (A) to the transischial line (B). (c) The horizontal center of rotation is the horizontal distance measured from the center of the femoral head to a medial landmark, such as the teardrop. 


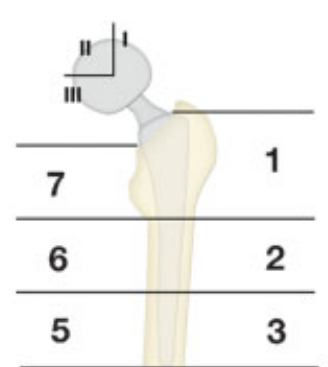

4

a

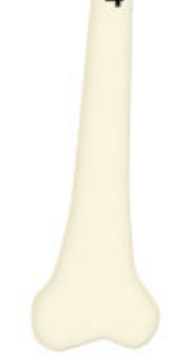

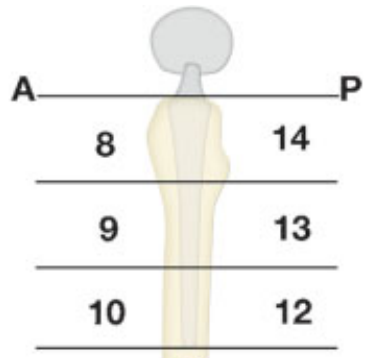

11

b

Fig. 3 (a) Frontal and (b) lateral schematics of the left hip showing the three DeLee and Charnley zones of the acetabular component (I-III) and the 14 Gruen zones of the femoral component (1-7 on the frontal view and $8-14$ on the lateral view). Note that on the lateral view, the lesser trochanter is a posterior structure. A, anterior; P, posterior.

predictive value for osseous integration is $96.9 \%$ for acetabular components. ${ }^{29}$ The proximal portion of the noncemented femoral stem has a porous coating where bony ingrowth can occur to help secure the prosthesis. These areas of endosteal new bone that contact the porous surfaces are called spot welds ( - Fig. 7). Calcar atrophy (i.e., loss of bone mineral density of the proximal medial femoral cortex) also indicates implant stability. ${ }^{5,30}$ Stress shielding refers to transfer of the normal load from the femoral neck and intertrochanteric region to the proximal femoral diaphysis. It is most commonly seen in Gruen zone 1, but it can involve the entire femoral shaft. It is not a sign of loosening and does not lead to osteolysis or an increased revision rate. However, the demin-

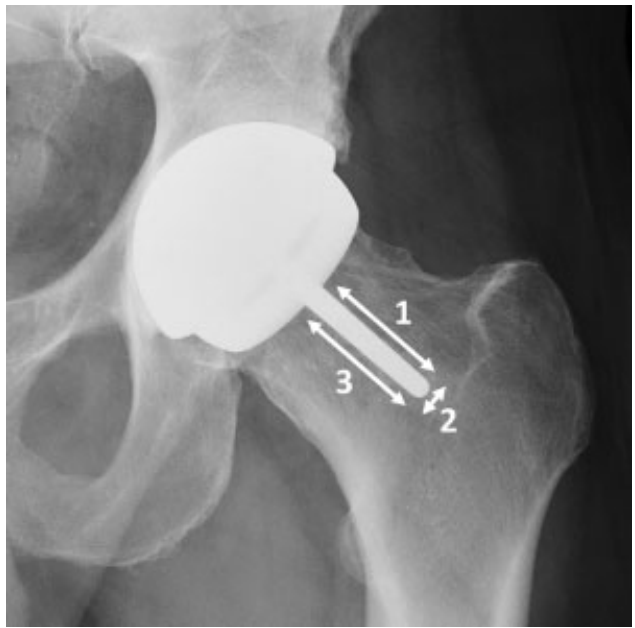

Fig. 4 Frontal radiograph of a left hip resurfacing arthroplasty (same patient as in Fig. 1) showing the three zones around the femoral stem as defined by Amstutz et al. The acetabular zones are the same as for a total hip arthroplasty.

eralization of the bone may present challenges during revision surgeries. ${ }^{24,31-34}$ The distal periprosthetic femoral cortex may also increase in thickness and density (hypertrophy) as a response to load transfer to that region. ${ }^{5,32,34}$

\section{Mechanical (Aseptic) Loosening}

Aseptic loosening is the most common cause for THA failure and is the reason for up to $60 \%$ of arthroplasty revisions (-Fig. 8). ${ }^{11,35}$ Diagnosis of mechanical loosening requires a negative infection work-up. ${ }^{2}$

Loosening is defined as implant motion detected with mechanical manipulation during surgery. ${ }^{2,5}$ Motion and mechanical stress may promote synoviocyte migration into interfaces of the arthroplasty with the bone and/or cement. These synoviocytes release cytokines and also form "fibrous" or "synovial-like" membranes, also termed "membrane formation," which can precede loosening. ${ }^{36,37}$ As a general rule, for cemented and
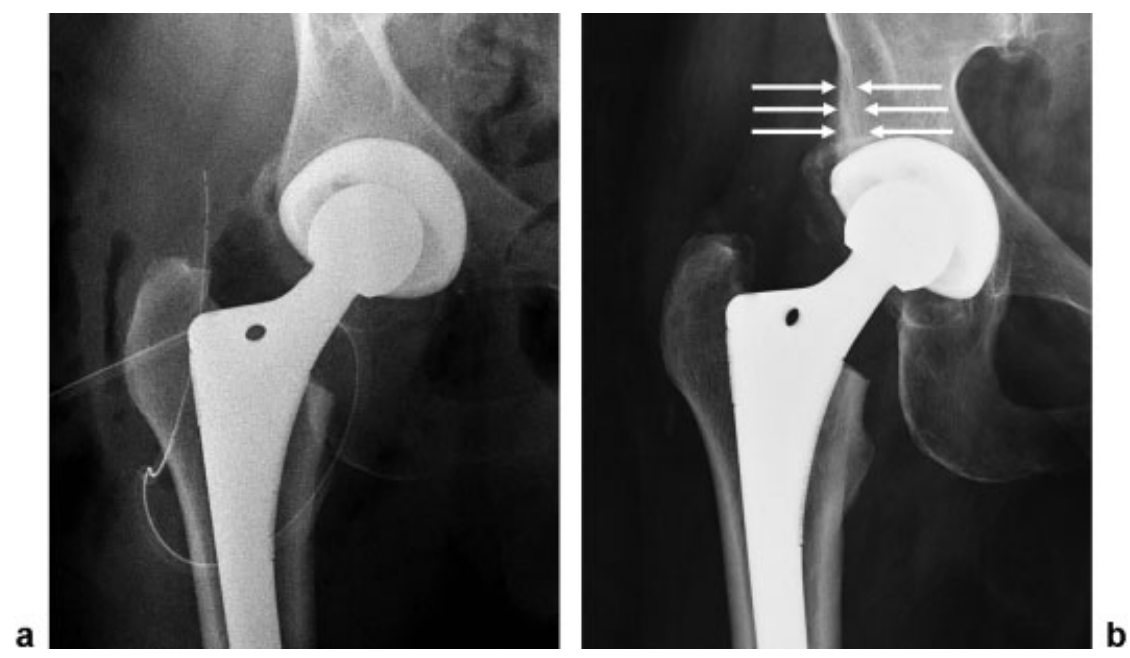

Fig. 5 A 73-year-old woman with noncemented right total hip arthroplasty. (a) Portable frontal radiograph in the immediate postoperative period shows gross anatomical position of the implant, a surgical drain, and soft tissue gas. (b) Frontal radiograph of the right total hip arthroplasty $\sim$ 6 weeks later shows superolateral buttressing (arrows). 


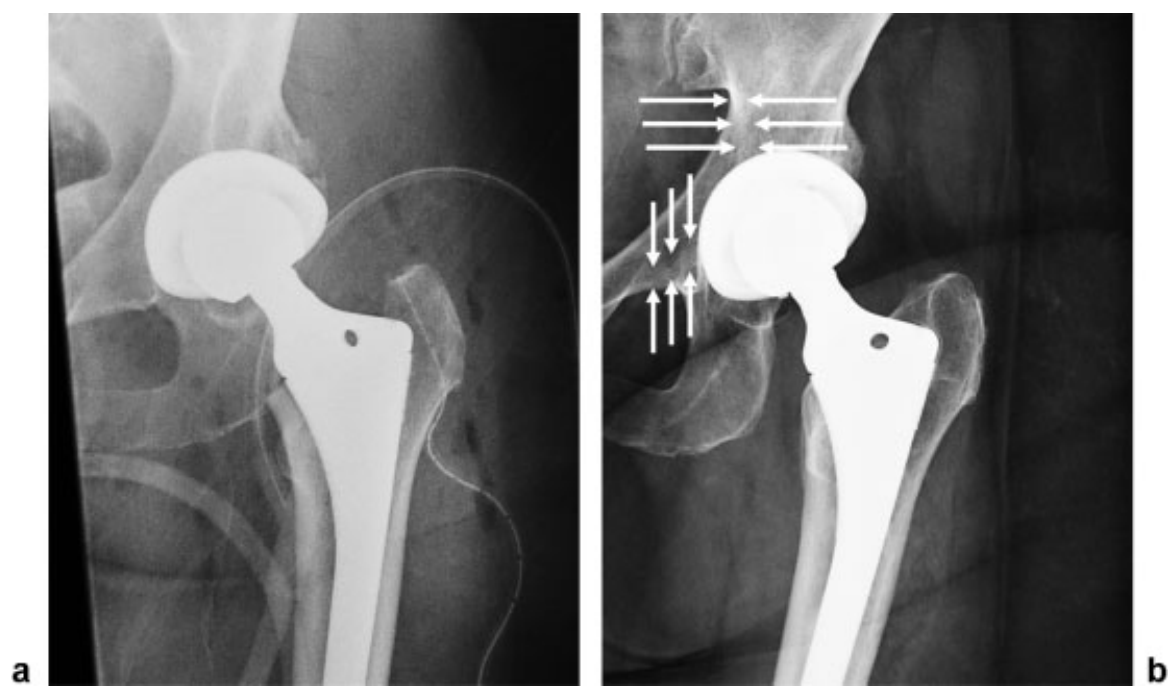

Fig. 6 A 64-year-old woman with noncemented left total hip arthroplasty. (a) Portable frontal radiograph in the immediate postoperative period shows gross anatomical position of the implant, a surgical drain, and soft tissue gas. (b) Frontal radiograph of the left total hip arthroplasty almost a year and a half later shows radial trabeculae (horizontal arrows) and inferomedial buttressing (vertical arrows).

noncemented acetabular and femoral components, periprosthetic lucency $>1 \mathrm{~mm}$ is probably clinically insignificant. Lucency of 1 to $2 \mathrm{~mm}$ in thickness probably indicates membrane formation, and a lucency $>2 \mathrm{~mm}$ in thickness, especially if it is new and the lucency is not parallel to the arthroplasty (i.e., divergent), indicates loosening. 2,24

For noncemented acetabular components, migration or periprosthetic lucency that is present in all three zones, appears or progresses after 2 years, or is $>2 \mathrm{~mm}$ in any zone are $95 \%$ sensitive and $100 \%$ specific for loosening. ${ }^{38}$ For cemented acetabular components, Hodgkinson et al found that if lucency was found in zone I only, zones I and II only, or in zones I, II, and III, the chance of finding mechanical loosening at surgery was $7 \%, 71 \%$, and $94 \%$, respectively. ${ }^{39} \mathrm{~A}$
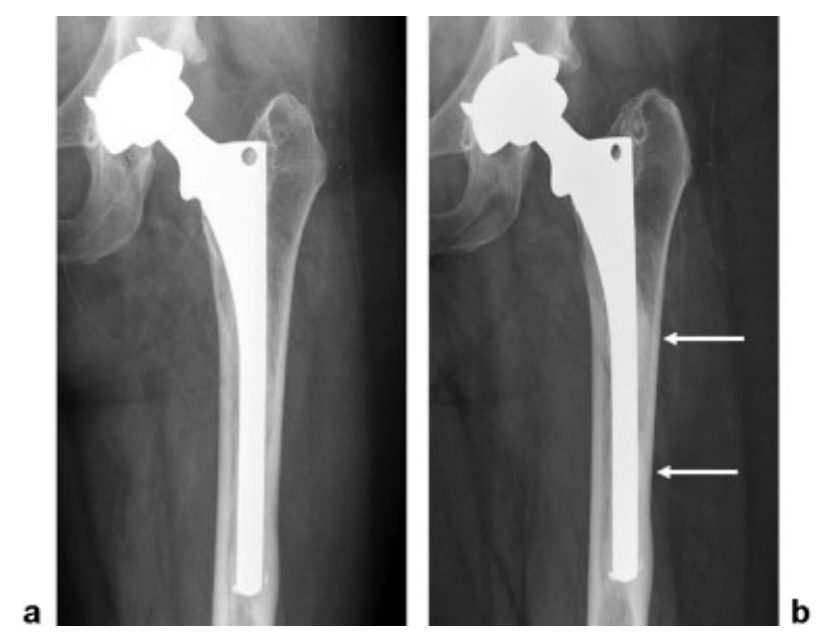

Fig. 7 A 62-year-old woman with revised noncemented left total hip arthroplasty for asymmetric liner wear resulting in metal-on-metal wear. (a) Frontal radiograph soon after revision shows anatomical position of the implant. Thickening of the lateral femoral cortex in Gruen zones 3 and 4 as well as punctate metallic debris near the femoral greater trochanter were present prior to revision. (b) Frontal radiograph $\sim 4.5$ years later shows development of spot welds (arrows). change in inclination of the acetabular component $>4$ degrees or movement $>4 \mathrm{~mm}$ with cement fracture also is consistent with loosening. ${ }^{40}$

For noncemented femoral components, endosteal scalloping and a change in position of the arthroplasty, including migration and progressive subsidence, indicate loosening. Subsidence of the femoral component is defined as a change in the distance from the tip of the greater trochanter to the lateral shoulder of the prosthesis. Up to $2 \mathrm{~mm}$ of subsidence within the first year may be normal, but progression after 2 years and/or subsidence $>5 \mathrm{~mm}$ is abnormal for both noncemented and cemented components (- Fig. 9). ${ }^{2,24,40} \mathrm{~A}$ pedestal, or a new shelf of bone distal to the femoral stem tip, indicates distal load transfer and can be present if the prosthesis is stable. This should not be considered a sign of motion unless periprosthetic lucency around the stem tip is also seen (- Fig. 10). ${ }^{5}$ For cemented femoral components, cement fracture and component migration are diagnostic of loosening. ${ }^{41}$ Malik et al showed an association between lucency in Gruen zones 3 and 5 and early aseptic loosening. ${ }^{42}$

\section{Infection}

After a THA, the risk of infection is $\sim 1 \%$, with a higher prevalence after revision surgeries. ${ }^{43,44}$ However, some evidence suggests that periprosthetic infections are underdiagnosed. ${ }^{44}$ The radiographic findings are often similar to those seen in aseptic loosening, and the diagnosis is made with a combination of history, laboratory values, and aspiration of periprosthetic fluid, which should be sent for microbiology analysis and cell count. ${ }^{7,8}$ Aspiration has a higher predictive value if it is used as a confirmatory test rather than a screening test and should be reserved for patients who have a high suspicion for infection. ${ }^{44}$

\section{Particle Disease and Metallosis}

Particle disease is the body's response to foreign particles (metal, cement, polyethylene) that are shed as a result of wear 

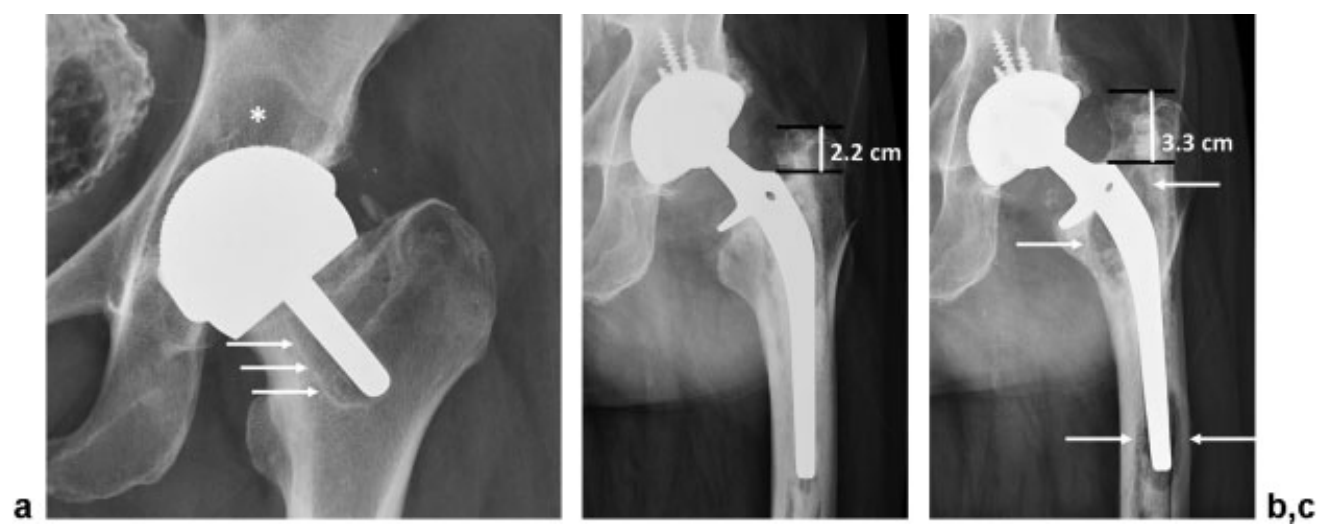

Fig. 8 (a) Frontal radiograph of the left hip in a 56-year-old woman with a left hip resurfacing arthroplasty. There is periprosthetic lucency at Amstutz zone 3 of the femoral stem (arrows) and at DeLee and Charnley zones I and II of the acetabular component (asterisk). The femoral neck appears short, which may have resulted in leg length discrepancy and contributed to the loosening of the femoral stem. (b) Frontal radiograph of the left hip in an 81-year-old man with a left total hip arthroplasty with a cemented femoral component and a noncemented acetabular component. There is no periprosthetic or bone-cement interface lucency to suggest loosening. (c) Frontal radiograph of the left hip in the same patient as in (b) $\sim 7$ years later shows periprosthetic lucencies at Gruen zones 1, 3, 4, 5, and 7 of the femoral component (arrows), $1.1 \mathrm{~cm}$ of subsidence, and varus position of the femoral stem, consistent with loosening.

of the prosthesis and results in a foreign body granulomatous reaction. Larger pieces are walled off in fibrous tissue, and giant cells surround smaller pieces. Pieces $<1 \mathrm{~mm}$ are ingested by macrophages and multinucleated giant cells, which may result in cytokine release and surrounding

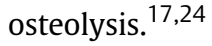

Many of the findings of particle disease overlap with infection and aseptic loosening. However, multiple punctate metallic particles or beads (bead shedding) around the prosthesis or asymmetric location of the femoral head component
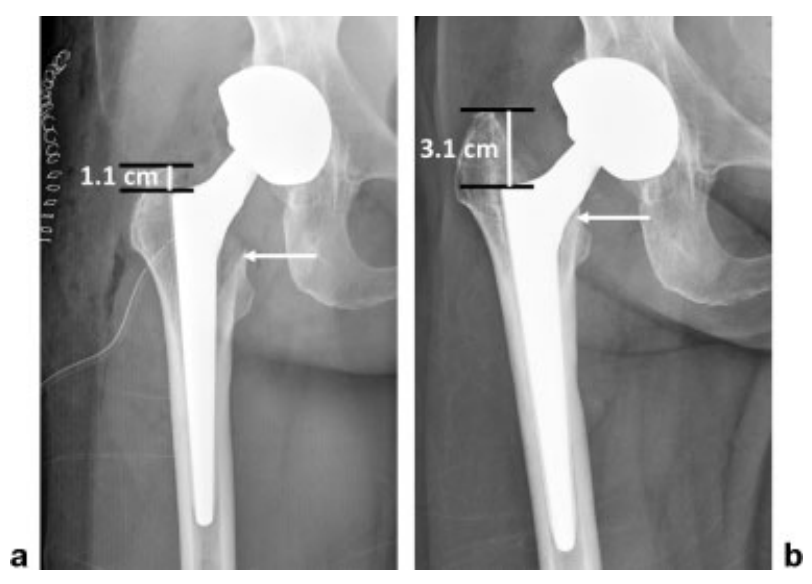

Fig. 9 A 63-year-old woman with noncemented right total hip arthroplasty. (a) Portable frontal radiograph in the immediate postoperative period shows gross anatomical position of the implant, a surgical drain, surgical skin staples, and soft tissue gas. The superolateral corner of the femoral stem is located $1.1 \mathrm{~cm}$ inferior to the superior tip of the greater trochanter. The triangular lucency at Gruen zone 7 is due to surgical resection (arrow). (b) Frontal radiograph of the right hip $\sim 5$ months later shows that the triangular surgical resection defect at Gruen zone 7 allowed interval telescoping of the total hip arthroplasty into the femur until the proximal medial aspect of the femoral stem contacted the proximal medial femoral shaft (arrow). The superolateral corner of the femoral stem is now located $3.1 \mathrm{~cm}$ inferior to the superior tip of the greater trochanter, indicating $2.0 \mathrm{~cm}$ of subsidence. within the acetabular component (asymmetric liner wear) indicate the presence of a foreign body granulomatous reaction (-Fig. 11 and - Fig. 12). ${ }^{24}$

\section{Fracture}

The prevalence of periprosthetic fractures has been increasing, with reported rates reaching as high as $18 \%$, probably due to an elderly population that is living longer and with more severe osteopenia. Osteolysis and prosthetic loosening are also risk factors for fracture. Periprosthetic fractures are responsible for $9 \%$ of single-stage revision surgeries.

Intraoperative periprosthetic fractures can occur during joint dislocation, reaming, broaching, joint reduction, or arthroplasty insertion. Noncemented arthroplasties require a greater force to secure a stable fit in the femoral medullary cavity and therefore are at greater risk for fracture than cemented arthroplasties. Fractures are also more common during revision surgeries than primary surgeries and for a longer stem compared with a shorter stem. ${ }^{45,46}$ Intraoperative fractures are usually nondisplaced, in the anterior shaft of the femur, and begin at the tip of the femoral stem and progress vertically ( $\mathbf{F i g . 1 3}$ ). ${ }^{24}$ Late periprosthetic fractures may be insufficiency fractures in the pubic ramus, acetabulum, greater trochanter, or femoral shaft. ${ }^{47-49}$

Periprosthetic femoral fractures can be described using the Vancouver classification, seen in - Fig. 14. Types B1 and B2 are the most common periprosthetic fractures in primary (61\%) and secondary (44\%) THAs, respectively. The fractures can also be categorized as a simple cortical perforation, a nondisplaced linear fracture, or a displaced and unstable fracture, because the category affects the management. ${ }^{50-52}$

Acetabular fractures are much less common than femoral fractures and are very uncommon during primary arthroplasty placement. Intraoperatively, the fractures may occur during dislocation, reaming, or impaction, and they are more common when placing a noncemented acetabular component. Acetabular fractures as a late complication occur either 

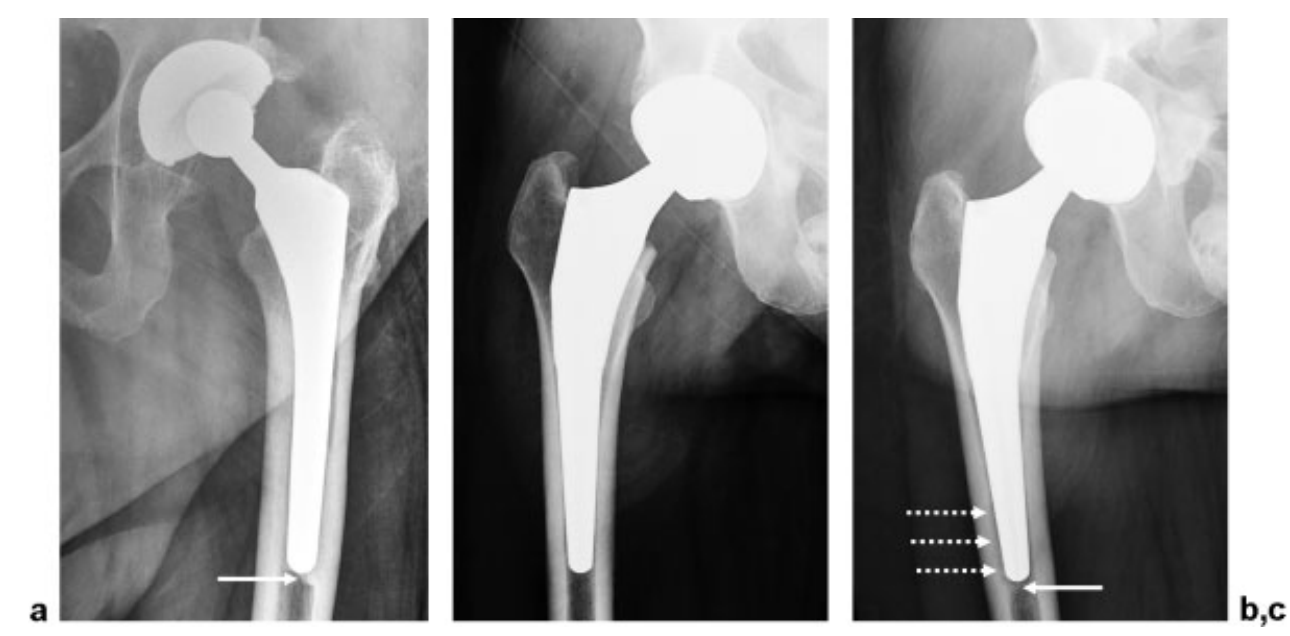

Fig. 10 (a) Frontal radiograph of the left hip in a 66-year-old man with a noncemented left total hip arthroplasty. There is a pedestal of bone at the tip of the femoral component that partially bridges the medullary canal (arrow). There is no periprosthetic lucency to suggest loosening. (b) Frontal radiograph of the right hip in a 58-year-old woman with a noncemented right total hip arthroplasty. There is no periprosthetic lucency to suggest loosening. (c) Frontal radiograph of the right hip in the same patient as in (b) 9 months later shows a pedestal of bone at the tip of the femoral component that partially bridges the medullary canal (solid arrow). Additionally, there is new periprosthetic lucency at Gruen zone 3 of the femoral component consistent with loosening (dotted arrows).

due to severe trauma or pathologic processes in the surrounding bone. ${ }^{53}$

RA fractures occur in the femoral neck, and some proposed risk fractures include acetabular component notching of the femoral neck, quality of cement penetration (both inadequate and excessive), cysts in the residual femoral head and neck, uncovered areas of bone reamed during surgery, osteopenia, avascular necrosis of the femoral neck, preoperative and postoperative vertical and horizontal center of rotation offset, and preoperative and postoperative leg length discrepancy. ${ }^{17,54-56}$
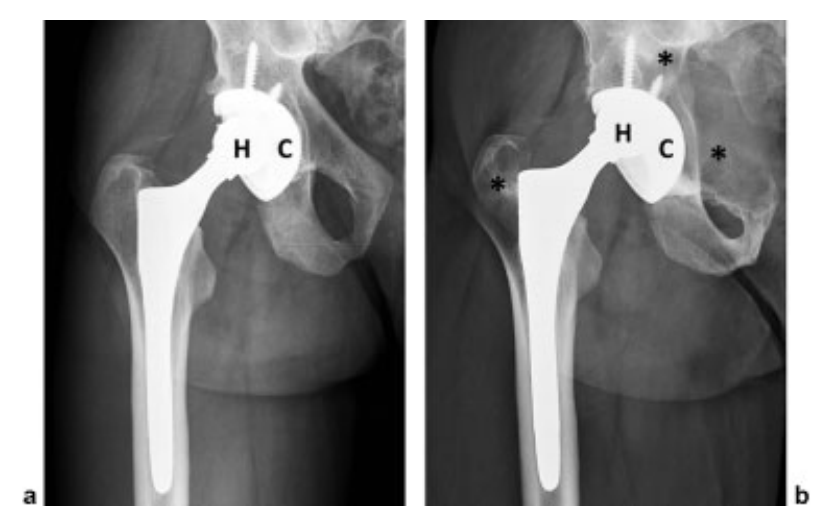

Fig. 11 A 57-year-old man with right total hip arthroplasty. (a) Frontal radiograph of the right hip shows no periprosthetic lucency, and the femoral head $(\mathrm{H})$ is well centered within the acetabular cup (C). The inclination angle of the acetabular cup measures 63 degrees, which is abnormally high. (b) Frontal radiograph of the right hip $\sim 10$ years later shows that the femoral head $(\mathrm{H})$ is no longer centered within the acetabular cup (C). Additionally, there is extensive periprosthetic lucency involving Gruen zone 1 of the femoral component and DeLee and Charnley zones I, II, and III of the acetabular component (asterisks). The acetabular lucency extends into and involves most of the superior pubic ramus. The periprosthetic lucencies are consistent with osteolysis, and the constellation of findings is most compatible with asymmetric liner wear and particle disease.

\section{Dislocation}

Dislocation remains the second most common reason for surgical revision and the most common immediate postoperative complication. Dislocation rates are $3.2 \%$ with a posterior approach, $2.2 \%$ with an anterolateral approach, $1.3 \%$ with a transtrochanteric approach, and $0.6 \%$ with a direct lateral approach. Although highest dislocation rates are reported with a posterior approach, it remains a popular approach because the anterolateral and direct lateral approaches require violating the abductor muscles, and the
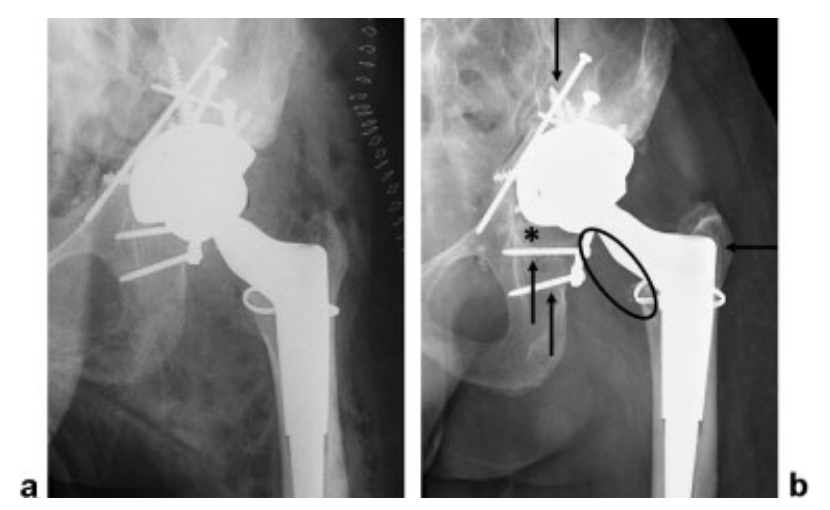

Fig. 12 A 48-year-old woman with noncemented left total hip arthroplasty. (a) Portable frontal radiograph in the immediate postoperative period shows gross anatomical position of the implant, surgical skin staples, and soft tissue gas. Numerous additional screws projecting over the left bony pelvis are related to open reduction and internal fixation of complex left acetabular and iliac bone fractures. (b) Frontal radiograph of the left hip approximately a year and a half later shows numerous punctate metallic radiodensities projecting medial to the prosthetic femoral neck and proximal femoral shaft remnant (oval). Additionally, there are developing periprosthetic lucencies at Gruen zone 1 of the femoral component (horizontal arrow), DeLee and Charnley zone III of the acetabular component (asterisk), as well as around the screws of the inferior aspect of the acetabular plate and screw construct and one of the screws at Delee and Charnley zone II of the acetabular component (vertical arrows). The constellation of findings is consistent with metallosis and loosening. 

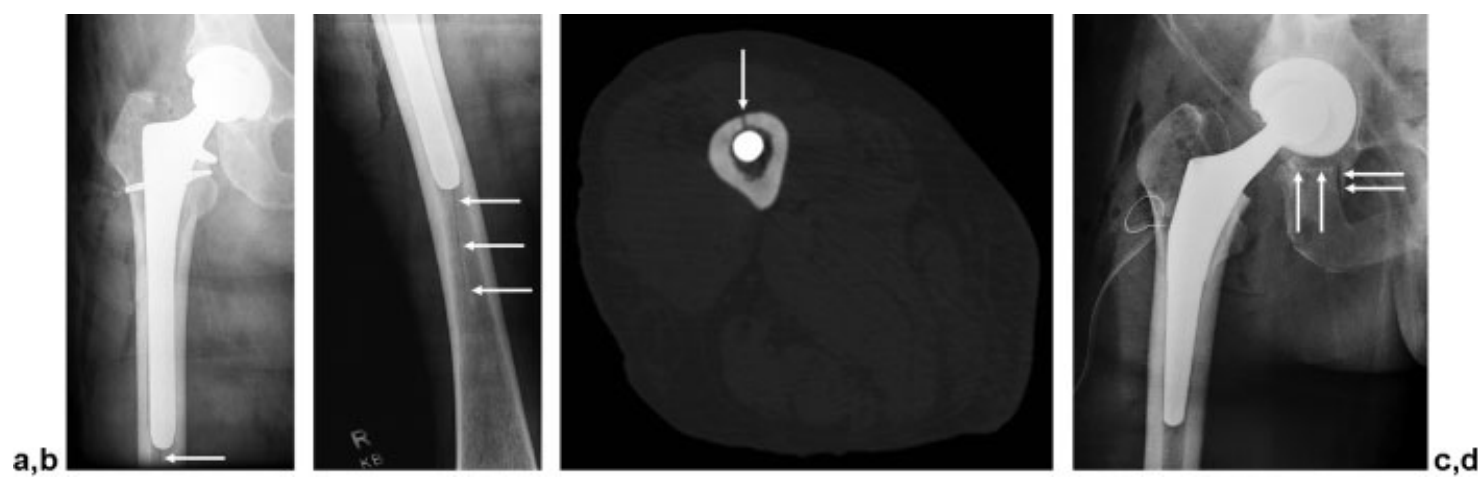

Fig. 13 (a) Perioperative portable frontal radiograph of the right hip in a 70-year-old woman shows a noncemented total hip arthroplasty in gross anatomical position and soft tissue gas. At the inferior edge of the radiograph is a vertical linear lucency projecting adjacent to the tip of the femoral stem, concerning for a periprosthetic femur fracture (arrow). (b) Additional portable frontal radiograph of the right femur in the same patient as in (a) shows the full extent of the vertical lucency projecting adjacent to the tip of the femoral stem that remains concerning for a periprosthetic femur fracture (arrows). (c) Axial noncontrast computed tomography image through the mid-right femur in the same patient as in (a) and (b) obtained the following day confirms the periprosthetic femur fracture involving the anterior femoral cortex (arrow). (d) Perioperative portable frontal radiograph of the right hip in a 50-year-old man shows a noncemented total hip arthroplasty in gross anatomical position, a surgical drain, and soft tissue gas. There is also a periprosthetic fracture through the superior aspect of the right ischium (arrows).

a

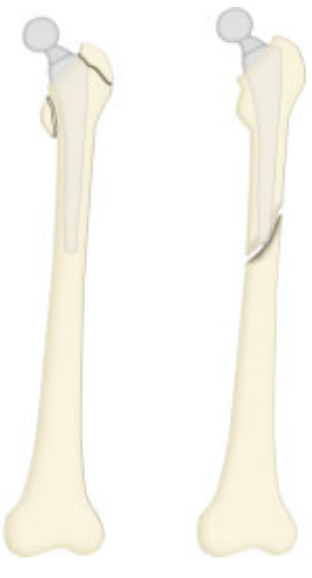

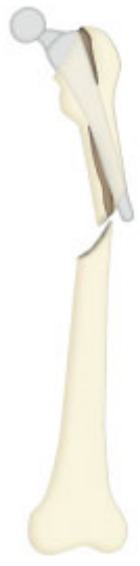
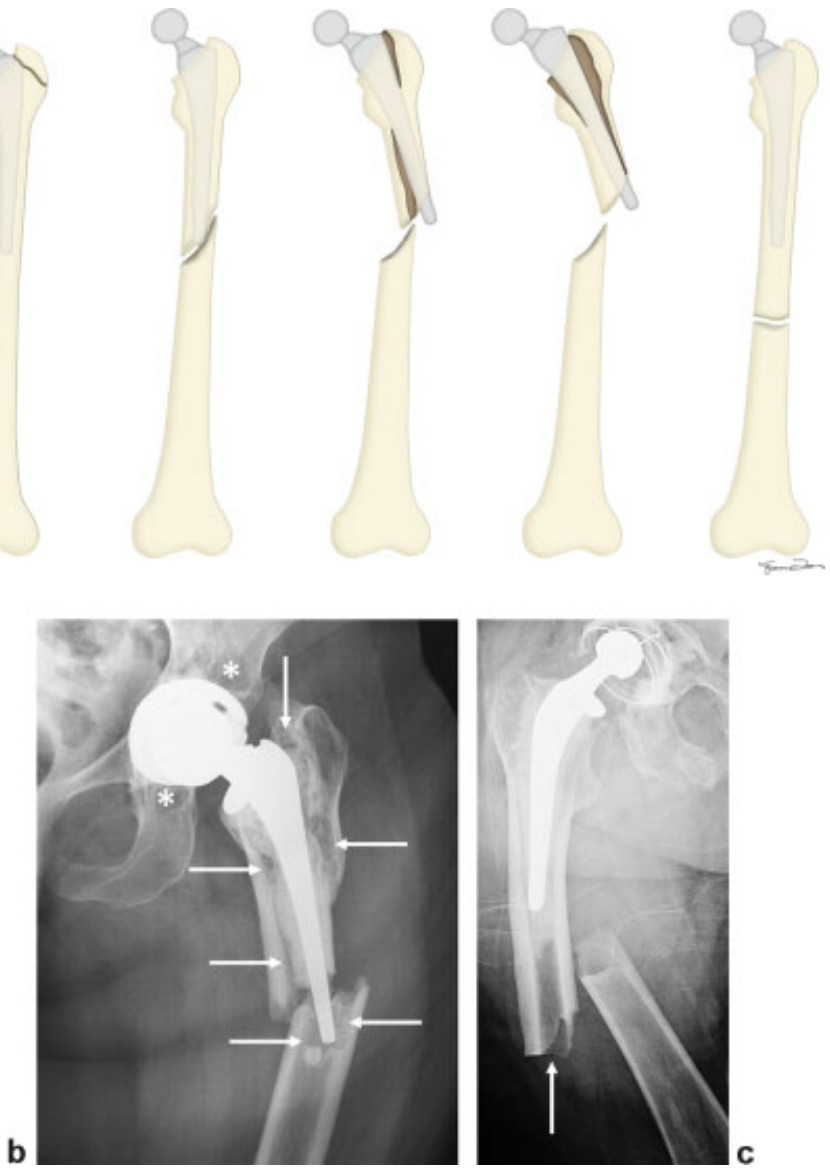

Fig. 14 Vancouver classification for periprosthetic femoral fractures. (a) Schematics of a left femur show that the fractures are divided anatomically: Type $A$ is a greater or lesser trochanteric fracture, type B is in the diaphysis just distal to the tip of the stem, and type $C$ is far distal to the stem and essentially a nonrelated separate fracture. Type B is further divided: Type B1 has adequate bone stock and shows no radiographic findings of loosening, type $B 2$ is a loose component with adequate bone stock, and type B3 is a loose component with inadequate bone stock. (b) An 80-year-old woman with a left total hip arthroplasty with a cemented femoral component and a noncemented acetabular component. There is a periprosthetic femur fracture at the level of the distal aspect of the femoral stem. Additionally, there are extensive periprosthetic and bone-cement interface lucencies involving essentially all of the femoral component (arrows) and DeLee and Charnley zones I and III of the acetabular component (asterisks). The constellation of findings represents a Vancouver type B3 periprosthetic fracture. (c) An 85 -year-old woman with a right total hip arthroplasty with cemented femoral and acetabular components. There is a periprosthetic femur fracture centered several centimeters distal to the tip of the femoral stem, representing a Vancouver type $C$ periprosthetic fracture. Also noted is superolateral location of the femoral head with respect to the acetabular cup, indicating asymmetric liner wear. 
transtrochanteric approach requires a greater trochanteric osteotomy. ${ }^{12,57}$ In the acute postoperative period, dislocation is due to a loose pseudocapsule. Dislocation as a late complication ( $>5$ years from the time of replacement) is more common in older women and usually due to progressive laxity of the pseudocapsule. ${ }^{58}$ Acetabular inclination or version outside of the safe zones, abnormally high or low vertical center of rotation of the arthroplasty, and abductor denervation, avulsion, or muscle atrophy also increase the likelihood for dislocation. 24,59

\section{Impingement}

Iliopsoas tenosynovitis and capsular impingement can also be sources of pain following arthroplasty. ${ }^{42,60}$ Head-neck geometry and ratio, a lateralized horizontal position of the acetabular cup, an oversized acetabular cup, and residual acetabular osteophytes increase the likelihood of iliopsoas tendon impingement. ${ }^{40,42,61,62}$ Fluoroscopic or ultrasound-guided injections of the iliopsoas tendon sheath can provide diagnostic information and short-term symptomatic relief, but definitive treatment may require iliopsoas tendon release. ${ }^{63-66}$ Bulky heterotopic ossification, which appears at $\sim 3$ to 4 weeks and matures over $\sim 3$ to 6 months, may also limit range of motion or cause pain from lateral soft tissue impingement. Less pronounced heterotopic ossification may also generate pain, but this topic is controversial. ${ }^{67,68}$

\section{Neoplasm}

Neoplasm is a rare cause of periprosthetic pain and should be considered if the patient has an atypical presentation (e.g., rapid progression of symptoms) and a history of neoplasm. Focal metastasis may have a more rounded appearance compared with periprosthetic osteolysis and/or soft tissue mass. Bloody periprosthetic aspirate may be associated with malignancy and prompt cytological analysis. ${ }^{69,70}$

\section{Acknowledgments}

We gratefully acknowledge the help of our illustrator Sue Loomis.

\section{References}

1 Health data interactive. Centers for Disease Control and Prevention Web site. Available at: http://www.cdc.gov/nchs/hdi.htm

2 Fritz J, Lurie B, Miller TT. Imaging of hip arthroplasty. Semin Musculoskelet Radiol 2013;17(3):316-327

3 Mancuso CA, Salvati EA, Johanson NA, Peterson MG, Charlson ME. Patients' expectations and satisfaction with total hip arthroplasty. J Arthroplasty 1997;12(4):387-396

4 Gross TP, Liu F. Outcomes after revision of metal-on-metal hip resurfacing arthroplasty. J Arthroplasty 2014;29(9, Suppl):219-223

5 Engh CA, Massin P, Suthers KE. Roentgenographic assessment of the biologic fixation of porous-surfaced femoral components. Clin Orthop Relat Res 1990;(257):107-128

6 Hozack W, Parvizi J, Bender B. Surgical Treatment of Hip Arthritis: Reconstruction, Replacement, and Revision. Philadelphia, PA: Saunders Elsevier; 2009

7 Spangehl MJ, Masri BA, O'Connell JX, Duncan CP. Prospective analysis of preoperative and intraoperative investigations for the diagnosis of infection at the sites of two hundred and two revision total hip arthroplasties. J Bone Joint Surg Am 1999;81(5): 672-683

8 Sanzén L, Carlsson AS. The diagnostic value of C-reactive protein in infected total hip arthroplasties. J Bone Joint Surg Br 1989;71(4): 638-641

9 Delaunay CP. Metal-on-metal bearings in cementless primary total hip arthroplasty. J Arthroplasty 2004;19(8, Suppl 3):35-40

10 Clarke MT, Lee PTH, Arora A, Villar RN. Levels of metal ions after small- and large-diameter metal-on-metal hip arthroplasty.J Bone Joint Surg Br 2003;85(6):913-917

11 Mulcahy H, Chew FS. Current concepts of hip arthroplasty for radiologists: part 1, features and radiographic assessment. AJR Am J Roentgenol 2012;199(3):559-569

12 Brown TE, Cui Q Mihalko WM, Saleh KJ, eds. Arthritis and Arthroplasty: The Hip. Philadelphia, PA: Saunders Elsevier; 2009

13 Amstutz HC, Beaulé PE, Dorey FJ, Le Duff MJ, Campbell PA, Gruen TA. Metal-on-metal hybrid surface arthroplasty: two to six-year follow-up study. J Bone Joint Surg Am 2004;86-A(1):28-39

14 Jacobs JJ, Hallab NJ, Skipor AK, Urban RM. Metal degradation products: a cause for concern in metal-metal bearings? Clin Orthop Relat Res 2003;(417):139-147

15 Naudie D, Roeder CP, Parvizi J, Berry DJ, Eggli S, Busato A. Metal-onmetal versus metal-on-polyethylene bearings in total hip arthroplasty: a matched case-control study. J Arthroplasty 2004;19(7, Suppl 2):35-41

16 Clarke MT, Lee PTH, Villar RN. Dislocation after total hip replacement in relation to metal-on-metal bearing surfaces. J Bone Joint Surg Br 2003;85(5):650-654

17 Amstutz HC, Campbell PA, Le Duff MJ. Fracture of the neck of the femur after surface arthroplasty of the hip. J Bone Joint Surg Am 2004;86-A(9):1874-1877

18 Shimmin AJ, Bare J, Back DL. Complications associated with hip resurfacing arthroplasty. Orthop Clin North Am 2005;36(2): 187-193, ix ix.

19 Little CP, Ruiz AL, Harding IJ, et al. Osteonecrosis in retrieved femoral heads after failed resurfacing arthroplasty of the hip. J Bone Joint Surg Br 2005;87(3):320-323

20 Case CP. Chromosomal changes after surgery for joint replacement. J Bone Joint Surg Br 2001;83(8):1093-1095

21 Frank ED, Long BW, Smith BJ. Merrill's Atlas of Radiographic Positioning \& Procedures. 11th ed. St. Louis, MO: Mosby Elsevier; 2007

22 Sutherland CJ. Radiographic evaluation of acetabular bone stock in failed total hip arthroplasty. J Arthroplasty 1988;3(1):73-79

23 D'Lima DD, Urquhart AG, Buehler KO, Walker RH, Colwell CW Jr. The effect of the orientation of the acetabular and femoral components on the range of motion of the hip at different headneck ratios. J Bone Joint Surg Am 2000;82(3):315-321

24 Manaster BJ. From the RSNA refresher courses. Total hip arthroplasty: radiographic evaluation. Radiographics 1996;16(3): 645-660

25 De Haan R, Pattyn C, Gill HS, Murray DW, Campbell PA, De Smet K. Correlation between inclination of the acetabular component and metal ion levels in metal-on-metal hip resurfacing replacement. J Bone Joint Surg Br 2008;90(10):1291-1297

26 De Haan R, Campbell PA, Su EP, De Smet KA. Revision of metal-onmetal resurfacing arthroplasty of the hip: the influence of malpositioning of the components. J Bone Joint Surg $\mathrm{Br}$ 2008;90(9): 1158-1163

27 DeLee JG, Charnley J. Radiological demarcation of cemented sockets in total hip replacement. Clin Orthop Relat Res 1976;(121):20-32

28 Gruen TA, McNeice GM, Amstutz HC. "Modes of failure" of cemented stem-type femoral components: a radiographic analysis of loosening. Clin Orthop Relat Res 1979;(141):17-27

29 Moore MS, McAuley JP, Young AM, Engh CA Sr. Radiographic signs of osseointegration in porous-coated acetabular components. Clin Orthop Relat Res 2006;444(444):176-183 
30 Vresilovic EJ, Hozack WJ, Rothman RH. Radiographic assessment of cementless femoral components. Correlation with intraoperative mechanical stability. J Arthroplasty 1994;9(2):137-141

31 Engh CA Jr, McAuley JP, Sychterz CJ, Sacco ME, Engh CA Sr. The accuracy and reproducibility of radiographic assessment of stressshielding. A postmortem analysis. J Bone Joint Surg Am 2000;82$\mathrm{A}(10): 1414-1420$

32 Bodén H, Adolphson P, Oberg M. Unstable versus stable uncemented femoral stems: a radiological study of periprosthetic bone changes in two types of uncemented stems with different concepts of fixation. Arch Orthop Trauma Surg 2004;124(6):382-392

33 Kwon DG, Lee TJ, Kang JS, Moon KH. Correlation between stress shielding and clinical outcomes after total hip arthroplasty with extensively porous coated stems. J Arthroplasty 2013;28(10): $1728-1730$

34 Bugbee WD, Culpepper WJ II, Engh CA Jr, Engh CA Sr. Long-term clinical consequences of stress-shielding after total hip arthroplasty without cement. J Bone Joint Surg Am 1997;79(7): 1007-1012

35 Chiang PP, Burke DW, Freiberg AA, Rubash HE. Osteolysis of the pelvis: evaluation and treatment. Clin Orthop Relat Res 2003; (417):164-174

36 Seel MJ, Hafez MA, Eckman K, Jaramaz B, Davidson D, DiGioia AM III. Three-dimensional planning and virtual radiographs in revision total hip arthroplasty for instability. Clin Orthop Relat Res 2006;442(442):35-38

37 Berman AT, McGovern KM, Paret RS, Yanicko DR Jr. The use of preoperative computed tomography scanning in total hip arthroplasty. Clin Orthop Relat Res 1987;(222):190-196

38 Udomkiat P, Wan Z, Dorr LD. Comparison of preoperative radiographs and intraoperative findings of fixation of hemispheric porous-coated sockets. J Bone Joint Surg Am 2001;83-A(12): 1865-1870

39 Hodgkinson JP, Shelley P, Wroblewski BM. The correlation between the roentgenographic appearance and operative findings at the bone-cement junction of the socket in Charnley low friction arthroplasties. Clin Orthop Relat Res 1988;(228):105-109

40 Yoder SA, Brand RA, Pedersen DR, O'Gorman TW. Total hip acetabular component position affects component loosening rates. Clin Orthop Relat Res 1988;(228):79-87

41 Harris WH, McCarthy JC Jr, O'Neill DA. Femoral component loosening using contemporary techniques of femoral cement fixation. J Bone Joint Surg Am 1982;64(7):1063-1067

42 Malik A, Maheshwari A, Dorr LD. Impingement with total hip replacement. J Bone Joint Surg Am 2007;89(8):1832-1842

43 Phillips CB, Barrett JA, Losina E, et al. Incidence rates of dislocation, pulmonary embolism, and deep infection during the first six months after elective total hip replacement. J Bone Joint Surg Am 2003;85-A(1):20-26

44 Bauer TW, Parvizi J, Kobayashi N, Krebs V. Diagnosis of periprosthetic infection. J Bone Joint Surg Am 2006;88(4):869-882

45 Berry DJ. Epidemiology: hip and knee. Orthop Clin North Am 1999; 30(2):183-190

46 Meek RMD, Garbuz DS, Masri BA, Greidanus NV, Duncan CP. Intraoperative fracture of the femur in revision total hip arthroplasty with a diaphyseal fitting stem. J Bone Joint Surg Am 2004; 86-A(3):480-485

47 Christiansen CG, Kassim RA, Callaghan JJ, Marsh JL, Schmidt AH. Pubic ramus insufficiency fractures following total hip arthroplasty. A report of six cases. J Bone Joint Surg Am 2003;85-A(9): 1819-1822

48 Kanaji A, Ando K, Nakagawa M, Fukaya E, Date H, Yamada H. Insufficiency fracture in the medial wall of the acetabulum after total hip arthroplasty. J Arthroplasty 2007;22(5):763-767
49 Pritchett JW. Fracture of the greater trochanter after hip replacement. Clin Orthop Relat Res 2001;(390):221-226

50 Lindahl H, Malchau H, Herberts P, Garellick G. Periprosthetic femoral fractures classification and demographics of 1049 periprosthetic femoral fractures from the Swedish National Hip Arthroplasty Register. J Arthroplasty 2005;20(7):857-865

51 Rayan F, Dodd M, Haddad FS. European validation of the Vancouver classification of periprosthetic proximal femoral fractures. J Bone Joint Surg Br 2008;90(12):1576-1579

52 Naqvi GA, Baig SA, Awan N. Interobserver and intraobserver reliability and validity of the Vancouver classification system of periprosthetic femoral fractures after hip arthroplasty. J Arthroplasty 2012;27(6):1047-1050

53 Chitre A, Wynn Jones H, Shah N, Clayson A. Complications of total hip arthroplasty: periprosthetic fractures of the acetabulum. Curr Rev Musculoskelet Med 2013;6(4):357-363

54 Wera GD, Gillespie RJ, Petty C, Petersilge WJ, Kraay MJ, Goldberg VM. Revision of hip resurfacing arthroplasty. Am J Orthop 2010; 39(8):E78-E83

55 Schmalzried TP, Silva M, de la Rosa MA, Choi E-S, Fowble VA Optimizing patient selection and outcomes with total hip resurfacing. Clin Orthop Relat Res 2005;441(441):200-204

56 Ritter MA, Lutgring JD, Berend ME, Pierson JL. Failure mechanisms of total hip resurfacing: implications for the present. Clin Orthop Relat Res 2006;453(453):110-114

57 Masonis JL, Bourne RB. Surgical approach, abductor function, and total hip arthroplasty dislocation. Clin Orthop Relat Res 2002; (405):46-53

58 Miki H, Masuhara K. Arthrographic examination of the pseudocapsule of the hip after posterior dislocation of total hip arthroplasty. Int Orthop 2000;24(5):256-259

59 Roy BR, Binns MS, Horsfall H. Radiological diagnosis of abductor denervation after hip surgery. Skeletal Radiol 2001;30(2):117-118

60 Barrack RL. Preoperative planning for revision total hip arthroplasty. Clin Orthop Relat Res 2004;(420):32-38

61 Johnston RC, Brand RA, Crowninshield RD. Reconstruction of the hip. A mathematical approach to determine optimum geometric relationships. J Bone Joint Surg Am 1979;61(5):639-652

62 Odri GA, Padiolleau GB, Gouin FT. Oversized cups as a major risk factor of postoperative pain after total hip arthroplasty. J Arthroplasty 2014;29(4):753-756

63 Jerosch J, Neuhäuser C, Sokkar SM. Arthroscopic treatment of iliopsoas impingement (IPI) after total hip replacement. Arch Orthop Trauma Surg 2013;133(10):1447-1454

64 Heaton K, Dorr LD. Surgical release of iliopsoas tendon for groin pain after total hip arthroplasty. J Arthroplasty 2002;17(6):779-781

65 Rezig R, Copercini M, Montet X, Martinoli C, Bianchi S. Ultrasound diagnosis of anterior iliopsoas impingement in total hip replacement. Skeletal Radiol 2004;33(2):112-116

66 Staple TW, Jung D, Mork A. Snapping tendon syndrome: hip tenography with fluoroscopic monitoring. Radiology 1988; 166(3):873-874

67 Harwin SF. Trochanteric heterotopic ossification after total hip arthroplasty performed using a direct lateral approach. J Arthroplasty 2005;20(4):467-472

68 Spinarelli A, Patella V, Petrera M, Abate A, Pesce V, Patella S. Heterotopic ossification after total hip arthroplasty: our experience. Musculoskelet Surg 2011;95(1):1-5

69 O'Shea K, Kearns SR, Blaney A, Murray P, Smyth HA, McElwain JP. Periprosthetic malignancy as a mode of failure in total hip arthroplasty. J Arthroplasty 2006;21(6):926-930

70 Visuri T, Pulkkinen P, Paavolainen P. Malignant tumors at the site of total hip prosthesis. Analytic review of 46 cases. J Arthroplasty 2006;21(3):311-323 